\title{
Availability and affordability of essential medicines for children in the Western part of Ethiopia: implication for access
}

Edao Sado ${ }^{1 *}$ and Alemu Sufa ${ }^{2}$

\begin{abstract}
Background: Essential medicines (EMs) are those medicines which satisfy the priority health care needs of the population. Although it is a fundamental human right, access to essential medicines has been a big challenge in developing countries particularly for children. WHO recommends assessing the current situations on availability and affordability of EMs as the first step towards enhancing access to them. Therefore, the aim of this study was to assess access to EMs for children based on availability, affordability, and price.

Methods: We adapted the WHO and Health Action International tools to measure availability, affordability, and prices of EMs. We collected data on 22 EMs for children from 15 public to 40 private sectors' drug outlets in east Wollega zone. Availability was expressed as percentage of drug outlets per sector that stocked surveyed medicines on the day of data collection, and prices were expressed as median price ratio. Affordability was measured as the number of daily wages required for the lowest-paid government unskilled worker (1.04 US \$per day) to purchase one standard treatment of an acute condition or treatment for a chronic condition for a month.
\end{abstract}

Results: The average availability of essential medicines was $43 \%$ at public and $42.8 \%$ at private sectors. Lowest priced medicines were sold at median of 1.18 and 1.54 times their international reference prices (IRP) in the public and private sectors, respectively. Half of these medicines were priced at 0.90 to 1.3 in the public sector and 1.23 to 2.07 in the private sector times their respective IRP. Patient prices were $36 \%$ times higher in the private sector than in the public sector. Medicines were unaffordable for treatment of common conditions prevalent in the zone at both public and private sectors as they cost a day or more days' wages for the lowest paid government unskilled worker.

Conclusions: Access to EMs to children is hampered by low availability and high price which is unaffordable. Thus, further study on larger scale is critical to identify acute areas for policy interventions such as price and or supply, and to enhance access to EMs to children.

Keywords: Access to medicine, Children, Availability, Affordability, Prices of medicine, East wollega zone, Nekemte town, Ethiopia

\footnotetext{
* Correspondence: edaosd6@gmail.com

${ }^{1}$ Department of Pharmacy, Pharmacoepidemiology and Social Pharmacy

Unit, College of Medical and Health Sciences, Wollega University Ethiopia,

P.O. Box 395, Nekemte, Ethiopia

Full list of author information is available at the end of the article
} 


\section{Background}

Essential medicines (EMs), which satisfy the priority health care needs of the population, are backbone of health care and well being of individuals and populations [1-3]. Access to health care including EMs is a fundamental human right $[4,5]$. However, access to EMs has been a big challenge particularly in developing countries where more than half of their populations lack access to EMs [6] and majority of them are children [7].

Access to EMs is influenced by many interlinked factors such as the availability of medicines in the health care facilities, availability of sustainable financing and reliable health systems, rational selection and use of medicines, and affordable price $[1,8,9]$. In addition to these factors, they are also hardly found in the health care facilities in the recommended dosage for children $[10,11]$. This shows the inaccessibility of EMs for children in the developing countries where majority of child mortality is due to treatable diseases $[10,12]$. This is also true for Ethiopia, where more than $60 \%$ of child deaths are due to communicable diseases [13].

In order to escalate the accessibility of EMs for children, World Health Organization (WHO) developed Essential Medicine Lists for children (EMLc) in 2007 and it has also been promoting to formulate medicines in line with child body size through "make medicine child size" initiative $[10,14]$. The initiative aims to enhance the accessibility of safe, effective and quality medicines for children by promoting awareness and action through research, regulatory measures and changes in policy [10]. In line with the initiative, measuring the availability and prices of essential medicines in all sectors is a vital step to improve the accessibility of EMs for children [10].

Data on the availability and affordability of EMs help managers and policy makers to develop national policy, regulations and strategies to enhance access to them. However, there are fewer studies which provide these types of data for managers and policy makers. A study conducted on the availability and prices of the WHO's EMs for children in Guatemala revealed that availability of EMs is less than $50 \%$ in both private and public sectors, and prices for both lower priced medicines and higher priced medicines are higher than the respective international reference prices (IRP) and unaffordable, costing as much of 15 days' wages [10]. Similar finding is reported from the studies conducted in China $[15,16]$. There is also a survey conducted in fourteen central Africa countries which showed poor availability of EMs for children in both private and public sectors, and higher prices with considerable variations [17]. A national study conducted by Abiye and his colleagues in the western part of Ethiopia showed that availability of medicine is almost higher than $50 \%$, and medicines are sold at average of 0.65 and 0.94 times the IRP in the public and private sectors, respectively [18].
Although limited access to EMs for children is a global problem $[19,20]$, it is pressing issue in developing countries particularly for Sub-Sahara Africa countries [21]. Beyond that, the extent of the problem in Ethiopia is unknown. To the authors' best knowledge, the previous study on the availability and affordability of EMs in the western part of Ethiopia [18] only focused on the medicines for adult, and it was also not conducted according to WHO/Health Action International (HAI) methodology. So, there has been no study conducted on the availability and affordability of EMs for children in Ethiopia. Therefore, the purpose of this study was to assess the availability, prices and affordability of EMs for children to determine their accessibility for children.

\section{Methods}

\section{Study area and design}

A drug outlets based cross-sectional study was conducted in east Wollega zone, western part of Ethiopia. Data on the availability and prices of 22 EMs for children were collected in January, 2015 by adapting of the WHO/HAI standardized methodology [22].

\section{Selection of drug outlets}

Ten districts were randomly selected from the seventeen districts found in the east Wollega zone. There were a total of 56 drug outlets found in the ten selected districts surrounding Nekemte town, the capital city of the zone, and 40 drug outlets in the Nekemte town. These drug outlets were stratified into public, private and other (NGO drug outlets) sectors. From public sector, at least one drug outlet per district was randomly selected and included, but one hospital pharmacy, found in the surrounding district, was included purposely according to WHO/HAI recommendation [22]. From private sector, at least two drug outlets per district were randomly selected and included in the study. Private drug outlets were selected at a ratio of 2:1 compared to public drug outlets because the number of private drug outlets is $2-5$ times higher than public drug outlets in the selected districts, and private outlets serve as major sources of drugs for the public. However, all drug outlets of other sector found in the surrounding districts and the town were included purposely. We also included all three public drug outlets and one hospital pharmacy found in the town, purposely. Among 40 private outlets found in the town, 22 drug outlets were randomly selected and included in the study.

\section{Selection of medicines}

Twenty three EMs were identified based on the core list of the WHO EMLc specified by the "Better Medicines for Children Project" effort [23] and prevalence of diseases associated with childhood illness in the zone [East 
Wollega Health Department]. For each surveyed medicine, we collected data on the lowest priced, highest priced (instead of innovator/brand medicines), and its availability. But for antimalaria medicines, vitamin A and Zinc which are free of charge for public at public sector, we checked only their availability.

\section{Data collection and analysis}

We collected data on the availability and patient prices of medicines from 58 drug outlets during January, 2015. Among 58 drug outlets, 15 were from the public sector, 41 were from the private sector and two were from the other sector. Five data collectors were recruited and trained according to $\mathrm{WHO} / \mathrm{HAI}$ methodology and pretest was conducted in Ghimbi town, as it has close geographic proximity and population with similar socioeconomic status, and similar distribution of drug outlets. The data collectors collected information on availability and price using a standard data collection format specific to the EMs under survey Additional file 1. Then, "we entered data into the pre-programmed MS Excel Workbook provided as part of the WHO/HAI methodology" [22]. Data were double entered, cleared and analysed by using MS Excel Workbook provided by WHO/HAI Management Sciences for Health (MSH) 2012 part I. We presented the results by using tables and bar chart.

Though data were collected from 58 drug outlets, we analysed only the data collected from 55 drug outlets where 15 of them were from the public sector and 40 were from the private sector. We excluded data collected from one private drug outlet because the collected information was incomplete. Two drug outlets from other sector were also excluded as they do not fulfill the WHO/HAI recommendation criteria; the minimum number of drug outlets per sector should be four or greater than four [22].

Among the twenty three surveyed drugs, we included only twenty two drugs in analysis for both public and private sectors (Table 1). We excluded phenobarbitone (Phenobarbital) $20 \mathrm{mg} / 5 \mathrm{ml}$ elixir from analysis as the information was not yet collected because wrong targeted pack size was used in data collection formats.

\section{Measuring availability and affordability of medicines}

We used IRP of 2014 given by Management Sciences for Health (MSH) to facilitate national and international

Table 1 Lists of medicines surveyed in east Wollega zone

\begin{tabular}{|c|c|c|c|c|}
\hline$\overline{\text { No }}$ & Name & Strength & Dosage form & Indications \\
\hline 1. & Amoxicillin & $125 \mathrm{mg} / 5 \mathrm{ml}$ & Suspension & Infectious disease \\
\hline 2. & Amoxicillin & $250 \mathrm{mg} / 5 \mathrm{ml}$ & Suspension & Infectious disease \\
\hline 3. & Amoxicillin + Clavulanic Acid & $125 \mathrm{mg}+31.25 \mathrm{mg} / 5 \mathrm{ml}$ & Suspension & Infectious disease \\
\hline 4. & Amoxicillin + Clavulanic Acid & $250 \mathrm{mg}+62.5 \mathrm{mg} / 5 \mathrm{ml}$ & Suspension & Infectious disease \\
\hline 5. & Artesunate $^{a}$ & $60 \mathrm{mg}$ & Vial & Infectious disease \\
\hline 6. & Artemether + Lumefantrine ${ }^{a}$ & $20 \mathrm{mg}+120 \mathrm{mg}$ & Dispersible tab. & Infectious disease \\
\hline 7. & Chloramphenicol & $1 \mathrm{gm}$ & Vial & Infectious disease \\
\hline 8. & Carbamazepine & $100 \mathrm{mg} / 5 \mathrm{ml}$ & Syrup & Seizure disorder \\
\hline 9. & Ceftriaxone & $500 \mathrm{mg}$ & Vial & Infectious disease \\
\hline 10. & Cotrimoxazole & $40 \mathrm{mg}+200 \mathrm{mg} / 5 \mathrm{ml}$ & Suspension & Infectious disease \\
\hline 11. & Diazepam & $5 \mathrm{mg} / \mathrm{ml}$ & Ampoule & Seizure disorder \\
\hline 12. & Gentamicin & $20 \mathrm{mg} / 2 \mathrm{ml}$ & Ampoule & Infectious disease \\
\hline 13. & Ibuprofen & $100 \mathrm{mg} / 5 \mathrm{ml}$ & Suspension & Pain/inflammation \\
\hline 14. & ORS & To make $500 \mathrm{ml}$ & Powder & Dehydration \\
\hline 15. & Paracetamol & $120 \mathrm{mg} / 5 \mathrm{ml}$ & Syrup & Pain \\
\hline 16. & Paracetamol & $125 \mathrm{mg}$ & Suppository & Pain \\
\hline 17. & Penicillin G & 1 million IU & Vial & Infectious disease \\
\hline 18. & Procaine Penicillin G & 4 million IU & Vial & Infectious disease \\
\hline 19. & Salbutamol & 100 mcg/dose & Inhaler & Asthma \\
\hline 20. & Vitamin $A^{a}$ & 50,000 units & Capsule & Xerophthalmia \\
\hline 21. & Zinc Phosphate ${ }^{a}$ & $20 \mathrm{mg}$ & Dispersible tab & Dehydration \\
\hline 22. & Procaine Penicillin G & 4 million IU & Vial & Infectious disease \\
\hline
\end{tabular}

${ }^{a}$ Medicines free of charge to the public in the public sector 
comparisons. The MSH reference prices are the medians of recent procurement prices offered for generic products by not-for-profit suppliers to developing countries [24]. For cross-country comparisons purpose, we expressed prices as median price ratios (MPR). MPR is ratio of median local unit price relative to IRP [10]:

$$
\operatorname{MPR}=\frac{\text { Median.local.unit.price }}{\text { International.reference.unit.price }}
$$

We calculated MPR only for medicines with price data obtained from at least 4 drug outlets according to WHO/HAI recommendation. We used 1 US $\$=19.6758$ Ethiopian Birr exchange rate to calculate MPR, and it was commercial buying rate obtained from www.combanketh.et/currencyrate on the first day of data collection [25].

We measured availability by physical presence of EMs in the drug outlets on single visit during data collections. We expressed it as percentage of sampled drug outlets that have a particular EMs [26].

We assessed affordability for a standard treatment of top ten prevalent diseases in the childhood by comparing the total price of medicine at a standard dose according to Ethiopian standard treatment guideline for pediatrics to the daily wage of the lowest paid government unskilled employee at 20.5 Ethiopian birr (1.04 US \$) per day at the time of data collection. The cost of medicine for a full course of therapy for acute diseases and a 30days' supply of medicines for chronic diseases was calculated and changed to the day wage. Even though it is difficult to assess the real affordability of the medicine, we categorized as a medicine affordable "if it costs less than a day wage and unaffordable if it costs a day wage or more than a day wages" [10].

\section{Ethical considerations}

The study protocol was reviewed and approved by Institutional Research Review Committee of College of Medical and Health Sciences, Wollega University. The owners of drug outlets who participated were informed of the aims of study prior to participation, and a verbal consent was sought from each participated owner of drug outlet after explaining his/her right not to participate into the study. They were assured of confidentiality on the issues related to the business secret of premises by avoiding identifiers from the data collection tools.

\section{Results}

Availability of medicines on the day of data collection The results as shown in Table 2 revealed that the availability of lowest priced individual medicines varied by type of medicine and sector. It was found that average availability of the highest priced medicines was $1.2 \%$
Table 2 Average availability of individual lowest priced medicines in the public and private sectors

\begin{tabular}{|c|c|c|}
\hline \multirow[t]{2}{*}{ Name of medicine } & \multicolumn{2}{|c|}{$\begin{array}{l}\text { Percentage of outlets where } \\
\text { medicine was found }\end{array}$} \\
\hline & $\begin{array}{l}\text { Public sector } \\
\text { ( } n=15 \text { outlets) }\end{array}$ & $\begin{array}{l}\text { Private sector } \\
\text { ( } n=40 \text { outlets) }\end{array}$ \\
\hline Amoxicillin Suspension 125 mg & $80 \%$ & $90 \%$ \\
\hline Amoxicillin Suspension 250 mg & $60 \%$ & $80 \%$ \\
\hline 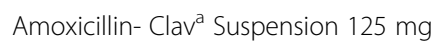 & $66.7 \%$ & $47.5 \%$ \\
\hline Amoxicillin- Clav $v^{a}$ Suspension 250 mg & $13.3 \%$ & $40 \%$ \\
\hline Artesunate $60 \mathrm{mg}$ vial & $26.7 \%$ & $0.0 \%$ \\
\hline $\begin{array}{l}\text { Artemether + Lumefantrine } \\
20 \mathrm{mg}+120 \mathrm{mg} \text { disp. tab }\end{array}$ & $66.7 \%$ & $0.0 \%$ \\
\hline Chloramphenicol 1gm vial & $46.7 \%$ & $20 \%$ \\
\hline Carbamazepine $100 \mathrm{mg} / 5 \mathrm{ml}$ syrup & $0.0 \%$ & $0 \%$ \\
\hline Ceftriaxone 500 mg vial & $26.7 \%$ & $22.5 \%$ \\
\hline $\begin{array}{l}\text { Cotrimoxazole } 40 \text { mg + } 200 \text { mg/5 ml } \\
\text { suspension }\end{array}$ & $100 \%$ & $90 \%$ \\
\hline Diazepam 5 mg/ml ampoule & $0.0 \%$ & $0.0 \%$ \\
\hline Gentamicin $20 \mathrm{mg} / 2 \mathrm{ml}$ ampoule & $0.0 \%$ & $0.0 \%$ \\
\hline Ibuprofen 100 mg/5 ml Suspension & $0.0 \%$ & $0.0 \%$ \\
\hline ORS to make $500 \mathrm{ml}$ soln. & $0.0 \%$ & $2.5 \%$ \\
\hline ORS to make $1000 \mathrm{ml}$ soln. & $40 \%$ & $87.5 \%$ \\
\hline Paracetamol $120 \mathrm{mg} / 5 \mathrm{ml}$ Syrup & $93.3 \%$ & $80 \%$ \\
\hline Paracetamol 125 mg Suppository & $93.3 \%$ & $87.5 \%$ \\
\hline Penicillin G 1million IU vial & $46.7 \%$ & $12.5 \%$ \\
\hline Procaine Penicillin G 4 million IU vial & $40 \%$ & $57.5 \%$ \\
\hline Salbutamol 100 mcg/dose inhaler & $46.7 \%$ & $52.5 \%$ \\
\hline Vitamin A 50,000 units Cap. & $20 \%$ & $0.0 \%$ \\
\hline Zinc Phosphate & $66.7 \%$ & $0.0 \%$ \\
\hline
\end{tabular}

Clav : - Clavulanic acid/Clavunate

(range 0-4.5\%) and $43.0 \%$ (range 10.7-75\%) for the lowest priced medicines in the public sector. Average availability in the private sector was 7.4\% (range 0$18.3 \%)$ for the highest priced medicines and $42.8 \%$ (range 6.5-77.1\%) for lowest priced medicines.

In the public drug outlets, generic medicines were the predominant product type available with $96 \%$ of medicines found as generics. Although vitamin A, zinc phosphate and antimalaria medicines are expected to be available in the public sector only, some of them such as artesunate $(26.7 \%)$ and vitamin A (20\%) had low availability. Carbamazepine $100 \mathrm{mg} / 5 \mathrm{ml}$ syrup, diazepam $5 \mathrm{mg} / \mathrm{ml}$ ampoule, gentamicin $20 \mathrm{mg} / 2 \mathrm{ml}$ ampoule and ibuprofen $100 \mathrm{mg} / 5 \mathrm{ml}$ suspension were not found in any drug outlets in both public and private sectors. The average availability of individual lowest price medicines in both public and private sectors was shown in Table 2. 


\section{Costs of medicines in public and private sectors}

To assess price variation of individual medicine across sectors, we calculated MPR of $13(n=13)$ lowest priced medicines. As shown in Table 3, MPR for lowest price medicines were found to be 1.18 times their IRP in the public sector. MPR for patient prices ranged from 0.58 to 2.86 times the IRP in the public sector for paracetamol suppository and penicillin $G$ injection respectively. Half of lowest priced medicines were priced at $0.90\left(25^{\text {th }}\right.$ percentile) to 1.3 ( $75^{\text {th }}$ percentile) times their IRP in the public sector, showing small variation within sector.

In the private sector, MPR for lowest priced medicines were found to be 1.54 times their IRP, and patient prices were ranged from 0.58 to 5.02 times the IRP for paracetamol suppository and ceftriaxone injection respectively. Half of the lowest priced medicines were priced at $1.23\left(25^{\text {th }}\right.$ percentile $)$ to $2.07\left(75^{\text {th }}\right.$ percentile $)$ times the IRP in the private sector, showing moderate variation in medicine price ratios across individual lowest priced medicines.

Highest priced medicines were found in less than four drug outlets of public sector. So, we did not calculate their MPR. But in the private sector, their MPR were 3.01 times IRP.

\section{Comparison of costs in the public and private sectors}

To compare patient prices across sectors, we used twelve $(n=12)$ lowest priced medicines found in at least four drug outlets in both public and private sectors, and we calculated their MPR as depicted in Fig. 1. Except for paracetamol suppository which had similar MPR in both public and private sectors, MPR were moderately higher in the private sector compared to the public sector but substantially higher for ceftriaxone injection. Median price ratios for these medicines were 1.18 and 1.61 in the public and private sector respectively; patient prices were $36 \%$ times higher in the private sector than in the public sector.

\section{Affordability of medicines for standard treatment regimens}

As shown in Table 4, 70 \% (7/10) of treatments of common childhood diseases prevalent in the zone with standard treatment [27] were unaffordable, as they cost a day's wage or more days' wages in both sectors. The unaffordability of lowest priced medicines in the public sector varies from 1.5 to 8.7 days' wages. Treatments of typhoid fever with chloramphenicol 1gm (8.7 days' wages) and infections due to susceptible organism with ceftriaxone $500 \mathrm{mg}$ (5.8 days wages) cost more than 5 days' wages, and they were the most unaffordable standard treatments in the public sector.

As shown in Table 4, the unaffordability of the lowest priced medicines varies from 1.8 to 30.7 days' wages in the private sector. The most unaffordable standard treatments were treatment of typhoid fever with chloramphenicol1gm (10.2 days' wages) and treatment of infections due to susceptible organism with ceftriaxone $500 \mathrm{mg}$ (30.7 days' wages).

\section{Discussions}

The findings of present study suggest that availability of children's EMs is below $50 \%$ in both public sector and private sector for both types of surveyed category of medicines. The average availability of lowest priced medicines for children is $43.0 \%$ in the public and $42.8 \%$ in the private sectors. Because of the general incomparability of survey results (due to variation in

Table 3 Median price ratios of thirteen lowest priced medicines in the public and private sectors $(n=13)$

\begin{tabular}{|c|c|c|}
\hline \multirow[t]{2}{*}{ Medicine name } & \multicolumn{2}{|c|}{ Lowest price medicines MPR ( $25^{\text {th }}-75^{\text {th }}$ percentile) } \\
\hline & Public sector & Private sector \\
\hline Amoxicillin Suspension 125 mg & $1.24(1.14-1.240)$ & $2.07(1.87-2.07)$ \\
\hline Amoxicillin Suspension 250 mg & $1.47(1.34-1.54)$ & $1.67(1.67-1.89)$ \\
\hline Amoxicillin- Clav Suspension 125 mg & $0.62(0.48-0.98)$ & $1.52(1.42-1.52)$ \\
\hline Amoxicillin- Clav Suspension 250 mg & $\mathrm{N} / \mathrm{A}$ & $1.05(0.91-1.11)$ \\
\hline Chloramphenicol 1 gm vial & $0.93(0.86-1.10)$ & $1.10(1.10-1.10)$ \\
\hline Ceftriaxone 500 mg vial & $0.95(0.89-1.03)$ & $5.02(4.47-5.02)$ \\
\hline Cotrimoxazole 40 mg + 200 mg/5 ml Suspension & $1.20(1.20-1.40)$ & $1.49(1.40-1.59)$ \\
\hline ORS to make $1000 \mathrm{ml}$ soln. & $1.53(1.15-1.93)$ & $2.55(1.78-2.55)$ \\
\hline Paracetamol 120 mg/5 ml Syrup & $1.17(0.90-1.32)$ & $1.23(0.87-1.47)$ \\
\hline Paracetamol 125 mg Suppository & $0.58(0.49-0.59)$ & $0.58(0.58-0.93)$ \\
\hline Penicillin G 1 million IU & $2.86(2.05-3.31)$ & $3.15(2.84-3.15)$ \\
\hline Procaine Penicillin G 4million IU & $1.27(1.14-1.41)$ & $1.84(1.63-2.04)$ \\
\hline Salbutamol 100 mcg/dose inhaler & $0.80(0.80-1.00)$ & $1.54(1.16-10.27)$ \\
\hline
\end{tabular}




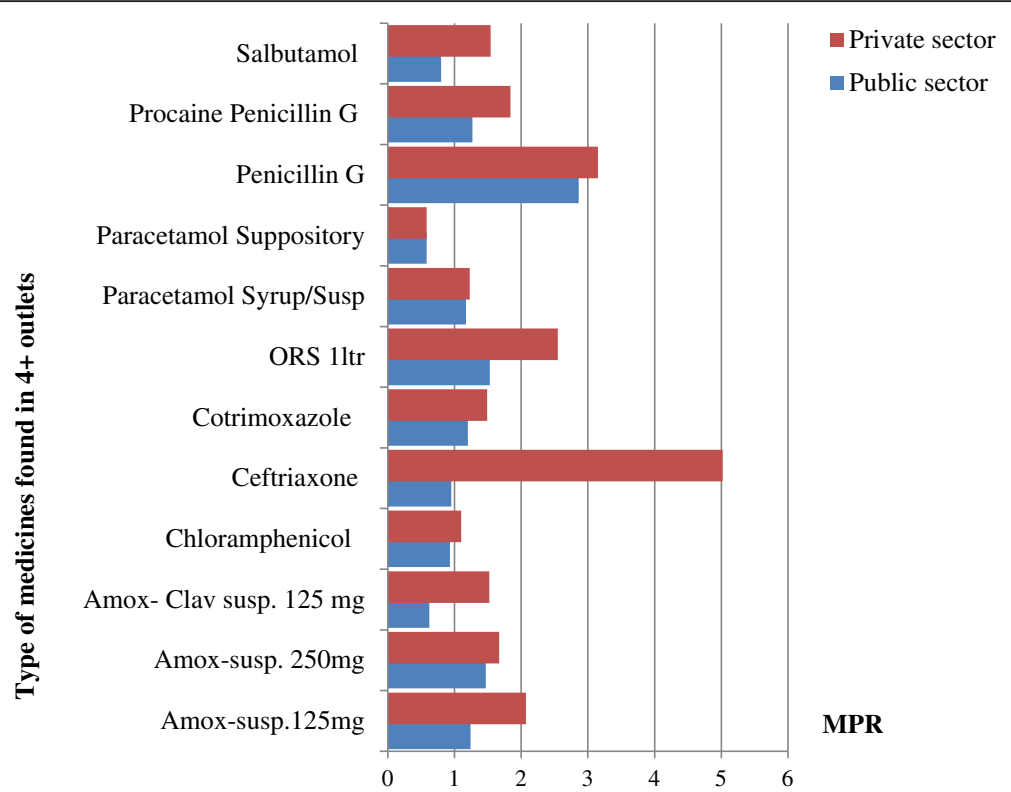

Fig. 1 Comparison of MPR of lowest price medicines found in atleast four drug outlets in public and private sectors

medicine pricing policy, methodology, types of prevalent disease, and medicine supply systems), it is difficult to make a comparative analysis of medicines availability. However, these findings are consistent with findings of study conducted by Anson et al. [10] in Guatemala which reported $46 \%$ in public sector and $35 \%$ in private sector. In contrast to the study conducted by Wang et al. [16] in China, this finding showed higher availability of lowest priced medicines in both public and private sectors, but it showed lower availability of highest priced medicines in both public and private sectors. The study also revealed that availability of medicines was higher in the public sector than in the private sector. This finding is also consistent with findings of studies conducted by Anson et al. [10] and Wang et al. [16].

Table 4 Affordability: number of days' wage of lowest paid unskilled government worker makes to purchase standard treatments

\begin{tabular}{|c|c|c|c|c|}
\hline \multirow[t]{2}{*}{ Conditions } & \multirow[t]{2}{*}{ Drug name, strength, dosage form } & \multirow[t]{2}{*}{ Treatment schedule } & \multicolumn{2}{|c|}{$\begin{array}{l}\text { Days wages to pay for } \\
\text { treatment }\end{array}$} \\
\hline & & & Public sector & Private sector \\
\hline Typhoid fever & Chloramphenicol 1gm vial & $\begin{array}{l}25 \mathrm{mg} / \mathrm{kg} * 14.5 \mathrm{~kg} \text { every } 6 \text { hours P.O. for } \\
14 \text { days }=20300 \mathrm{mg}=20.3 \mathrm{gm} 21 \text { vial [26]. }\end{array}$ & 8.7 & 10.2 \\
\hline Asthma & Salbutamol 100 mcg/dose inhaler & 1 inhaler of 200doses [27]. & 1.5 & 2.9 \\
\hline Dysentery & $\begin{array}{l}\text { Cotrimoxazole } 40 \mathrm{mg}+200 \mathrm{mg} / 5 \mathrm{ml} \\
\text { Suspension }\end{array}$ & $\begin{array}{l}24 \mathrm{mg} / \mathrm{kg} * 14.5 \mathrm{~kg} \mathrm{BID} \text { for } 5 \text { days }=3480 \mathrm{mg} .72 .5 \mathrm{ml} \\
\text { total for five days [27]. }\end{array}$ & 0.4 & 0.5 \\
\hline Severe Pneumonia & Penicillin G 1 million IU vial & $\begin{array}{l}50000 \text { units } / \mathrm{kg} \text { a } 14.5 \mathrm{~kg} \text { IV every } 4 \text { hours for at } \\
\text { least } 3 \text { days }=13.05 \text { millions of IU = } 14 \text { vial for } \\
\text { three days [27]. }\end{array}$ & 3.1 & 3.4 \\
\hline Acute otitis media & Amoxicillin 250 mg/5 ml Suspension & $\begin{array}{l}250 \mathrm{mg} / 5 \mathrm{ml} \mathrm{P.O.} \mathrm{TID} \mathrm{for} 10 \text { days for children } \\
\text { above } 6 \text { years of age }=150 \mathrm{ml}[27] .\end{array}$ & 1.6 & 1.8 \\
\hline Acute rhinosinusitis & Amoxicillin- Clav 156 mg/5 ml & $156 \mathrm{mg} / 5 \mathrm{ml}$ P.O. TID for 10dys = $150 \mathrm{ml}$ [27]. & 2.5 & 5.9 \\
\hline Acute bacterial tonsillitis & Amoxicillin- Clav 156 mg/5 ml & 156 mg/5 ml P.O. BID for ten days = $150 \mathrm{ml}$ [27]. & 2.5 & 5.9 \\
\hline Dehydration & ORS to make 1 litre & Moderate dehydration $75 \mathrm{ml} / \mathrm{kg} * 14.5=1087.5$ [27]. & 0.3 & 0.5 \\
\hline $\begin{array}{l}\text { Infections due to } \\
\text { susceptible organism }\end{array}$ & Ceftriaxone 500 mg vial & Child under $50 \mathrm{~kg}$ maximum 1gm for 7 days [27]. & 5.8 & 30.7 \\
\hline Pain/managenment & $\begin{array}{l}\text { Paracetamol } 125 \mathrm{mg} / 5 \mathrm{ml} \\
\text { Suspension }\end{array}$ & 5 year old child: 15 mg/kg*14.5 kg*4*3 $=104.4 \mathrm{ml}$ [27]. & 0.8 & 0.8 \\
\hline
\end{tabular}

*Weight of average 5 year old child in Ethiopia $=14.5 \mathrm{~kg}[13,34]$

P.O. per oral, BID two times per a day, TID three times per a day 
When we compare availability of medicines for children and for adults (or for overall population) perspective, the finding is lower than the finding of Abiye and his colleagues study in the western part of Ethiopia for public drug outlets [18]. But it is consistent for private sector and higher for public sector compared with findings of study conducted by Babar et al. [27] in Malaysia. It is also similar for public sector and lower for private sector from the findings reported by Bazargani et al. [29]. In opposite to the current findings, availability of medicines was higher in the private sector as compared to the public sector for mixed or general populations $[28,29]$. The low availability of medicines in the formulations preferable for use in children may limit access of medicines to children. To tackle this problem, health care professionals particularly pharmacists and nurses calculate the dose from adult dosage. This calculation may lead to incorrect dose use which might cause adverse drug effect [30].

EMs used for the treatment of chronic diseases in children were hardly found. This very low availability of medicines for treatment of chronic diseases in children consistent with government policy which is more focuses on the prevention rather than treatment [31]. Medicines offered free of charge from public sector are not available in any private sector and even their availability in public sector is low which may cause the inaccessibility of EMs for children. Though the most common causes of child morbidity and mortality are infectious diseases $[13,31]$, medicines used to treat common infectious disease in children like gentamicin is also not available in any drug outlets in both public and private sectors. This unavailability of common medicines for treatment of infectious diseases in the children might be due to lack of focuses from the government policy.

Like adult medications, the availability of child specific lowest priced medicines far exceeded that of highest priced medicines across all drug outlets in the public and private sectors. Highest priced medicines are unavailable in the $98.8 \%$ of public sector drug outlets. This may be due to generic procurement promotion in the public drug outlets. The availability of lowest price medicines in the drug outlets ranges from 5 to $45 \%$ in both public and private sectors. This is consistent with findings of study conducted by Robertson et al. [17] and his colleagues even though the perspective of study is not same.

The study also revealed that lowest priced medicines for children in both public and private sectors were sold at higher price than IRP. In the public sector, they are sold at 1.18 times their IRP and 1.54 times their IRP in the private sector. This finding is similar with the study conducted on the prices, availability and affordability of medicine in China [11] and findings of a study conducted by Cameron et al. and his colleague [32].
There was a notable variability in prices across drug outlets in private sector. This finding is consistent with study conducted on the availability, prices and affordability of essential medicines in Haiti [26]. The variability of price across the drug outlets in private sector might be the result of high market competition.

Lowest priced medicines are unaffordable for $70 \%$ of standard treatments of prevalent infectious diseases in both sectors as they cost a day's wage or more days' wages for lowest paid government employee. However, the extent they cost varies between the public and private drug outlets. This finding is consistent with the findings from study done on the availability, prices and affordability of the World Health Organization's essential medicines for children in Guatemala [10]. These costs do not include the costs of consultation and diagnostic tests, so that families who need medicines for more than one child may be confronted with more costs and extra days' wages. These findings are inconsistent with other studies of affordability of adult medicines which showed unaffordability of chronic medicines rather than drugs for infectious treatment for low income populations [10, 29] and consistent with study of affordability in the Haiti [26].

Although Ethiopia achieved Millennium Development Goal for reducing child mortality rate 2 years ahead of 2015 [33], the findings from this study suggest that accessibility of EMs for children is still low. Therefore, there is a need of improving the access to EMs for children which will help the country to achieve the global strategy for every child as part of the Sustainable Development Goals.

\section{Limitation of the study}

This study did not assess the medicine procurement prices and it was also conducted in the one zone due to logistical constraints.

\section{Conclusion}

This study was conducted to assess access to essential medicines for children based on their availability, price, and affordability. It has shown that availability of EMs for children use was below the recommended average in both public and private sectors. But the unavailability of EMs offered free of charge from public sector was pressing problem. Medicines were sold at higher price of IRPs and were unaffordable for people with low income in both public and private sectors.

The findings of this study suggest that access to EMs to children is hampered by low availability and high price which is unaffordability. Thus, further study should be conducted on larger scale by including medicines procurement price to identify acute areas for policy interventions such as price and or supply to enhance access to EMs to children. 


\section{Availability of data and materials}

The datasets supporting the conclusions of this article is included within the manuscript and supporting information.

\section{Additional file}

Additional file 1: Medicine Price Data Collection Form. (XLSX 16 kb)

\section{Abbreviations}

EMLc: essential medicine lists for children; EMs: essential medicines; HAl: health action international; IRP: international reference prices; MPR: median price ratios; MSH: management sciences for health; WHO: World Health Organization.

\section{Competing interests}

We declared that there was no fund for publication of this manuscript and we have no financial or non-financial competing interests.

\section{Authors' contributions}

ES, AS has made substantial contributions to conception and design the protocol; ES performed data collection and analysis and interpretation of the findings and wrote paper; ES, AS have been involved in drafting the manuscript; ES AS have given final approval of the version to be published; and agree to be accountable for all aspects of the work in ensuring that questions related to the accuracy or integrity of any part of the work are appropriately investigated and resolved.

\section{Acknowledgements}

We would like to thank Wollega University for funding of the study and College of Medical and Health Sciences for approving of this study. We would also like to extend our thanks to data collectors.

\section{Author details}

${ }^{1}$ Department of Pharmacy, Pharmacoepidemiology and Social Pharmacy Unit, College of Medical and Health Sciences, Wollega University Ethiopia, P.O. Box 395, Nekemte, Ethiopia. ${ }^{2}$ Department of Public health, Reproductive Health Unit, College of Medical and Health Sciences, Wollega University Ethiopia, P.O. Box 395, Nekemte, Ethiopia.

Received: 1 October 2015 Accepted: 8 March 2016

Published online: 15 March 2016

\section{References}

1. World Health Organization. Equitable access to essential medicines: a framework for collective action. WHO Policy Perspect Med. http://apps.who. int/iris/handle/10665/68571. Accessed 13 Mar 2015.

2. Mendis S, Fukino K, Cameron A, Laing R, Filipe A, Khatib O, et al. The availability and affordability of selected essential medicines for chronic diseases in six low- and middle-income countries. Bull World Health Organ. 2007;85:279-88.

3. Leisinger KM, Garabedian LF, Wagner AK. Improving access to medicines in low and middle income countries: corporate responsibilities in context. Southern Med Review. 2012:5(2):3-8.

4. Syhakhang L, Sengaloundeth S, Paphassarang C, Freudenthal S. Availability of essential drugs and sustainability of village revolving drug funds in remote areas of Lao PDR. Stud HSO\&P. 2008;519-43.

5. United Nations. Millennium Development Goal 8. Delivering on the Global Partnership for Achieving the Millennium Development Goals. New York: MDG Gap Task Force Report 2008; 2008.

6. Elamin El, Izham M, Ibrahim M, Abd M, Yousif E. Availability of essential medicines in Sudan. Sudan J public Heal. 2010;5(1):32-7.

7. Hill S, Yang A, Bero L. Priority medicines for maternal and child health: a global survey of national essential medicines lists. PLoS ONE. 2012;7(5): e38055.

8. Hinsch M, Kaddar M, Schmitt S. Enhancing medicine price transparency through price information mechanisms. Global Health. 2014;10(34):2-11.

9. Zaidi S, Bigdeli M, Aleem N, Rashidian A. Access to essential medicines in Pakistan: policy and health systems research concerns. PLoS ONE. 2013;8(5):e63515.
10. Anson A, Ramay B, Esparza A, Bero L. Availability, prices and affordability of the World Health Organization's essential medicines for children in Guatemala. Glob Health. 2012;8:22.

11. Jiang M, Yang S, Yan K, Liu J, Zhao J, Fang Y. Measuring access to medicines: a survey of prices, availability and affordability in Shaanxi province of china. PLoS ONE. 2013;8(8):e70836.

12. Hill S. Medicines prices and Malaysia—untangling the medicines Web. PLoS Med. 2007;4(3):2

13. Ethiopia Demographic and Health Survey 2011. Central Statistical Agency. Addis Ababa, Ethiopia: Central statistical Agency of Ethiopi; 2012.

14. Braine T. WHO to launch first essential medicines list for children. Bull World Health Organ. 2007;85(4):249-50.

15. Yang H, Dib HH, Zhu M, Qi G, Zhang X. Prices, availability and affordability of essential medicines in rural areas of Hubei Province. China Health Policy Plan. 2010:25(3):219-29.

16. Wang $X$, Yu Fang mail, Yang $S$, Jiang $M$, Yan $K$, Wu $L$, et al. Access to Paediatric Essential Medicines A Survey of Prices, Availability, Affordability and Price Components in Shaanxi Province, China. 2014. doi:10.1371/journal. pone.0090365.

17. Robertson J, Forte G, Trapsida JM, Hill S. What essential medicines for children are on the shelf? Bull World Health Organ. 2009;87:231-7.

18. Abiye Z, Tesfaye A, Hawaze S. Barriers to access: availability and affordability of essential drugs in a retail outlet of a public health center in South Western Ethiopia. J App Pharm Sci. 2013;3(10):101-5.

19. Fang $Y$, Wagner AK, Yang S, Jiang M, Zhang F, Ross-Degnan D. Access to affordable medicines after health reform: Evidence from two cross-sectional surveys in Shaanxi Province, western China. Lancet Glob Heal. 2013;1:4.

20. Emmerick ICM, Oliveira MA, Luiza VL, Azeredo TB, Bigdeli M. Access to medicines in Latin America and the Caribbean (LAC): a scoping study. BMJ Open. 2013;3(5). http://www.pubmedcentral.nih.gov/articlerender. fcgi?artid=3646181\&tool=pmcentrez\&rendertype. Accessed 22 Jan 2015.

21. Zainol ZA, Amin L, Jusoff K, Zahid A, Akpoviri F. Pharmaceutical patents and access to essential medicines in sub-Saharan Africa. African J Biotechnol. 2011;10(58):12376-88.

22. World Health Organization; Health Action International. Medicine prices, availability, affordability and price components. 2nd Edition. 2008, Switzerland.

23. Overview of methods for medicines availability and pricing surveys: Better Medicines for Children Project. http://www.who.int/childmedicines/ progress/ChildMeds_pricing_surveys.pdf. Accessed 10 Jul 2014

24. Management Sciences for Health. International Drug Price Indicator Guide. 2013th ed. Metford, Mass: MSH; 2014

25. Commercial Bank of Ethiopia. http://www.combanketh.et/More/ CurrencyRate.aspx. Accessed 18 Jan 2015.

26. Chahal HS, St Fort N, Bero L. Availability, prices and affordability of essential medicines in Haiti. J Glob Health. 2013;3:020405. http://www. pubmedcentral.nih.gov/articlerender.fcgi?artid=3868824\&tool= pmcentrez\&rendertype. Accessed 20 Jun 2015.

27. 27 Federal Democratic Republic of Ethiopia. Ministry of Health. Pediatric Hospital Care Pocket Book of Guidelines for the Management of Common IIInesses in Hospitals. 1st edition, 2010. P. 110,121,160,169,201,204,281

28. Babar ZUD, Ibrahim MIM, Singh H, Bukahri NI, Creese A. Evaluating drug prices, availability, affordability, and price components: Implications for access to drugs in Malaysia. PLoS Med. 2007;4(3):466-75.

29. Bazargani YT, Ewen M, De Boer A, Leufkens HGM, Mantel-Teeuwisse AK. Essential medicines are more available than other medicines around the globe. PLoS ONE. 2014;9(2):e87576

30. Goel P, Ross-Degnan D, Berman PSS. Retail pharmacies in developing countries: a behavior and intervention framework. Soc Sci Med. 1996;42(8):1155-61.

31. Federal Democratic Republic of Ethiopia. Ministry of Health. Health Sector Development Program IV 2010, Addis Ababa, Ethiopia: Ethiopian Central Statistical Authority.

32. Cameron A, Ewen M, Ross-Degnan D, Ball D, Laing R. Medicine prices, availability, and affordability in 36 developing and middle-income countries: a secondary analysis. Lancet. 2009;373:240-9.

33. Desalegn $H$, Solberg E, Kim JY. The global financing facility: country investments for every woman, adolescent, and child. Lancet. 2015;386(9989): 105-6. doi:10.1016/S0140-6736(15)61224-7.

34. World Health Organization. Child growth standards. http://www.who.int/ childgrowth/standards/weight_for_age/en/index.html. Accessed 22 Feb 2015. 